\title{
Response to Ottonello et al.: Non-erosive reflux disease patients are more complex than the sole endoscopy tells us
}

\author{
Karin Kislig • Clive H. Wilder-Smith • Michael M. Bornstein • \\ Adrian Lussi • Rainer Seemann
}

Received: 17 July 2013 / Accepted: 23 July 2013 /Published online: 9 August 2013

(C) Springer-Verlag Berlin Heidelberg 2013

We appreciate the interest in our publication [1] shown by Ottonello et al. and the reminder of their own useful contributions in the area of gastro-oesophageal reflux disease (GERD). The focused interest of our study was to assess whether halitosis, and in particular the production of volatile sulphur compounds (VSC), is associated with erosive changes in the upper gastrointestinal tract, as well as tongue coating. The presence of these changes by endoscopy and visual inspection was used for classification into one of two groups. Both groups were made up of patients with regular symptoms of reflux, as classified by the validated Reflux Disease Questionnaire [2]. The data showed that erosions do not lead to increased halitosis or VSC production.

Ottonello and co-workers raised the issue of the definition of non-erosive reflux in the comparator group, which is justified, even if it is not the central issue in the present study. It is well known that patients with regular symptoms of gastro-oesophageal reflux are comprised of those with increased reflux of acidic or weakly acidic gastric content, and also of those with a significant association between symptoms and reflux without excessive oesophageal acid exposure (hypersensitive oesophagus) [3]. Both are considered to have GERD and are further subdivided into those with

K. Kislig $(\bowtie) \cdot$ A. Lussi $\cdot$ R. Seemann

Department of Preventive, Restorative and Pediatric Dentistry,

University of Bern, Freiburgstrasse 7, Bern 3010, Switzerland

e-mail: karin.kislig@zmk.unibe.ch

C. H. Wilder-Smith

Gastroenterology Group Practice, Private Practice,

Bubenbergplatz 11, Bern 3011, Switzerland

M. M. Bornstein

Department of Oral Surgery and Stomatology, School of Dental Medicine, University of Bern, Freiburgstrasse 7, Bern 3010, Switzerland erosive and non-erosive reflux disease by endoscopy. A minority has symptoms without increased oesophageal acid reflux, reflux symptom association or erosions, who are described as having functional heartburn. Factors other than acid are likely to be relevant in this subgroup, including proteases, bile, a disrupted epithelial barrier, sensitization of peripheral or central nociception. For a more detailed characterization of the control group, 24-h pH impedance, as well as sensory testing, oesophageal biopsies and description of the composition of the refluxate would undoubtedly have been useful. We therefore fully concur with Ottonello et al. that 24$\mathrm{h} \mathrm{pH}$ impedance testing is required for the definition of nonerosive GERD in studies where this is the defined focus. However, this does not invalidate the main conclusion of the current paper that in patients with reflux symptoms and erosive changes halitosis or VSC production are not increased compared to patients with reflux symptoms without endoscopic erosive changes.

Finally, it is important to point out an inaccuracy in the brief summary by Ottonello and co-workers, namely, that for the determination of halitosis not only subjective questionnaires but also organoleptic and validated objective measures were employed.

Conflict of interest The authors declared no conflict of interest.

\section{References}

1. Kislig K, Wilder-Smith CH, Bornstein MM, Lussi A, Seemann R (2013) Halitosis and tongue coating in patients with erosive gastroesophageal reflux disease versus non-erosive gastroesophageal reflux disease. Clin Oral Invest 17:159-165

2. Nocon M, Kulig M, Leodolter A, Malfertheinder P, Willich SN (2005) Validation of the Reflux Disease Questionnaire for a German population. Eur J Gastroenterol Hepatol 17:229-233

3. Bredenoord AJ (2012) Mechanisms of reflux perception in gastroesophageal reflux disease: a review. Am J Gastroenterol 107:8-15 